\title{
Phenomenological Dialogue as Result of Evolution of the Main Strategy of the West European Philosophy in the XX Century
}

\author{
D. Adizbaeva ${ }^{1} \&$ A. Shoibekova ${ }^{1}$ \\ ${ }^{1}$ KazNAU, Almaty, Kazakhstan \\ Correspondence: A. Shoibekova, KazNMU, Almaty, Kazakhstan. E-mail: alima-almaty@mail.ru
}

Received: March 3, 2015 Accepted: April 15, 2015 Online Published: June 13, 2015

doi:10.5539/ass.v11n16p219 URL: http://dx.doi.org/10.5539/ass.v11n16p219

\begin{abstract}
This article discusses of three main orientations are distinctly allocated in the West European philosophy of the XX century.
\end{abstract}

Keywords: three main orientations, West European, philosophy, the XX century

\section{Introduction}

In the West European philosophy of the XX century three main orientations (strategy) are rather distinctly allocated, each of which unites a number of philosophical schools and concepts:

- existential and phenomenological, presented by phenomenology, existential philosophy and a philosophical hermeneutics; - analytical, being subdivided on logic-analytical (embodied, first of all, in logical positivism and focused, mainly, on the analysis of scientific knowledge) and the late analytical (covering a wide range the philosophical (language)of the concepts focused, first of all, on a natural language); - social and critical, presented by a set of concepts of the western Marxism, not differing ideological or organizational unity.

\section{Main Part}

Allocation of these three strategies only conditionally schematizes a motley picture of the West European philosophy of the XX century. However such schematization allows allocating common features which characterize the typological unity, consisting that in the met philosophical plan it belongs to "philosophy of the subject" at these various strategies of philosophizing. Its general characteristic which is initially showing in all three branches, is an installation on change (the person, scientific knowledge, society) with a support on the sovereign critical consciousness which only carrier is the philosophy. In the course of evolution of the main strategy of philosophy there is an internal transformation of the philosophizing which essence consists in overcoming of model of consciousness.

So, within existential and phenomenological strategy it is shown in transition from is subject reasonable analytics of human existence to a philosophical hermeneutics which, keeping pathos of existentially philosophizing, in general derivativeness of subjectivity from language: language is the way of a transfers of sense of words premised to any act of a reflection; before any philosophically aimed critical thought the world is for us always already the world interpreted in language. There is no such position out of language experience of the world which would allow making it a subject of external consideration.

Transition from consciousness model to language model within analytical strategy of philosophizing is connected with "pragmatically turn" in the analysis. The Logic-analytical philosophy which has found the fullest embodiment in an epistemology of logical empiricism was based, contrary to external visibility, on consciousness model which was shown also in treatment of language by logical empiricism. Absolutization of representative function of language contained the analysis of the knowledge embodied in language on model of the relation of the subject (psychological consciousness) to the outside world." Turn", connected with works of late Wittgenstein and the American pragmatically analysts Quine, Goodman and Sellers, meant, first of all, development of the pragmatically concept of value thanks to which communicative function of language moves to the forefront, and function of representation is treated as derivative of it. Over individual language game (life form), making "a world picture" - epistemical evidence, primary and prep remised concerning all rational representations of individual consciousness and acting owing to this fact as systematized mythology appears the quasisubject of knowledge in this case. 
From model consciousness's language models in evolution of the western Marxism can be tracked transition on an example of "the critical theory of society", presented by Horkheimer, Adorno's names and to Markus which was based on strategy of external criticism: being guided by ideals, humanity, it was necessary to reveal mindlessness dominating in capitalist society, to expose hidden - ideological - forms of suppression of the personality. The version of the western Marxism developed by Altyusser based on structuralize methodology, proves social a critical position not concept of the personality, and concept of social system.

In conceptual system of coordinates of social totality of ideology act, first of all, as structures which impose itself to a huge number of people, without passing through their consciousness.

Overcoming of model of consciousness caused cardinal change of an image of philosophy and nature of philosophizing. The being of this change can be recorded in three fundamental shifts:

- the epistemological and moral subject treated as autonomous, not involved and transparent for, is finally decentered. Subjectivity and intentionality any more aren't considered as something primary, and appear as function of forms of life and language systems; they constitute the world, and are elements of the world opened in language; - in connection with crisis of idea of the independent rational subject there is irrelevant an understanding of knowledge as representation according to which the learning subject resists to the world of objects independent of it and more or less precisely reproduces the last in the knowledge. The opposition of the subject and object since it is found out, on the one hand, that "objective data" always and with inevitability subjectively prev interpreted, and, with another is abolished that a condition of possibility of our knowledge of the "external" world is our intrinsic belonging to it. The prerequisite of propositional knowledge appears not articulated setting of the world to which we is effective are included; - consigns to the past traditional for philosophy an circumscribed of theoretical thinking from rhetoric, poetics and the literatures, proving purity and logical severity of philosophizing. Becomes obvious and presence at a philosophical discourse of figurative measurement, indirect communication, power effects is legitimated. Overcoming of model of consciousness in deeper current destabilizes a philosophical position as that as calls into question basic for it into distinctions of visibility and original reality, subjective opinion and knowledge. The opposition of visibility and reality passes through all western philosophical tradition began with distinction by Parmenid of the world of truth and the opinion world. The understanding of reality changed - in metaphysical tradition God was focus of a teleology order. But overcoming of philosophy of the subject eliminates instance. The back of similar disappearance of reality is some kind of crisis of intellectualism: in the western cultural tradition informative privileges of intellectuals were legalized by distinction of visibility. Laymen (or public), remaining in the visibility sphere, can possess only subjective and casual opinions, and only intellectuals (in particular, philosophers) by means of special discipline of thinking break to original reality and become exclusive owners of knowledge. But if distinction of visibility and reality is erased on what the right of philosophers to know and teach others can be based? On the basis of told it is possible to conclude that overcoming of philosophy of the subject in deeper current means crisis of model of knowledge for another and for another. Respectively, the key characteristic of modern philosophizing is change of communicative structure of philosophical knowledge. In a new situation distinctions between philosophical currents and schools are substantially erased, and the main line of opposition is connected rather with a question of destiny of philosophical rationality.

Language becomes not only a means of communication and a component of cognitive activity, but also the only environment in which all conscious and unconscious human life proceeds, the Philosophizing connected with the analysis of language, is not only style of thinking, but also a certain philosophical position. All problems are solved at language level, and criteria of the analysis are seen in the language, extra language, material and practical criteria of activity are leveled.

The main defect of theories of Quine, Feyerabend, Kuhn, according to Davidson, consists that, despite a relativism, language (and conceptual schemes) in them mediate between consciousness neutral reality. From here their concern in a question as our conceptual frameworks (predictions, the organizations, and coordination) belongs to experience (to the nature, reality, sensual data). It is actually necessary to reject in general idea of language as intermediary between I and reality or between our conventions and the nature. Language it only noise and the tags having metaphorical value, them it isn't necessary to subdivide on important literally and not having it. feature of counterargument of Davidson consists that, approving insolvency both old-neopositivistic dogmas of empiricism, and new, based on idea of the conceptual scheme, he insists on concept preservation an objective truth. For this purpose this concept needs to be transferred from the verification plane to the communication plane, "rejecting the dependence on concept of not interpreted reality as something being out of all schemes and science, we don't refuse concept of an objective truth... 
Certainly, the truth of offers is relative to language, but it is objective as far as it is possible.

However thus never it is necessary to forget that the truth is reached not on the basis of the principle of a retrieving of the general basis for various theories, and on the principle of trust to carriers of other language. "Having created the theory which coordinates trust and formal conditions for the theory, we will make everything that can be made for ensuring communication and anything bigger and it isn't required". All questions concerning the relation of consciousness and language to the Universe are causal, instead of questions of gnoseological representation.

The future of analytical philosophy is connected with the solution of a question on relationship between languages, consciousness the world. Consciousness, as well as language, equally inside and out of the world. It is that part of the world which represents both the world, and methods of research of this phenomenon - logical (aprioristic) also develop by means of transcendental argument (recognizing that when there are facts, they exist) So it is possible to speak about the world, or about its parts consisting of mental and speech essence, and about how we constructed of them something whole.

The concept of consciousness placing consciousness out of the world (as the part representing the world), skepticism concerning cognoscibility of the world generates. May we be convinced what is independent of language, but expressibility reality in it? Value of the term can't be based only on the theory. Allocation of the subject relation, its separation from value, assumes that our language isn't theoretically loaded so the result advances the basis.

Stroud considers that today the analytical philosophy (as a series of diverse concepts) is far from critical, negative or revolutionary, and in the main aspects became closer to the roots of the beginning of the century, in its interest to metaphysics, ontology revives.

The consciousness of a subject is connected with speech activity, i.e. consciousness propositional, as its deep characteristic (in a counterbalance intentionally). This consciousness not subject object because it is mediated by the speech. About real as real the analytical philosophy transforms the Ontological question to an analytical question understanding of ontology statements. Finding out the relation to a traditional philosophy of reason as practical reason (as possibility of consciousness to reason and prove the statements), analysts find underestimation of a role of the logical. Value of offers can't be clearly in detail and only the new conceptual it is developed in polemic with in detail - theoretical concepts of philosophy) gives the chance to understand assertive (affirmative) statements (their predicative forms).

In the latest American analytical philosophies of the consciousness (philosophy of mind), engaged studying of the mechanism of fixing of processes of consciousness in a natural language, deviation from the psychophysical parallelism theory towards the theory of identity spiritual and corporal is noticeable. The philosophy of consciousness is engaged in the conceptual analysis of the linguistic means used for the description and an explanation of processes of consciousness (and mentalities). The researches devoted to intentionally characteristics of consciousness move to the forefront, to problems of individual language and knowledge of other consciousness's, fixing in language of painful feelings, to various situations of imagination, mental predispositions to this or that behavior.

Thus, it becomes more difficult to keep it as a part of analytical disciplines everything, and the paradigm of the conceptual analysis of mentality is offered as avoiding cognitive and behaviorism extremes.

The modern perspective of philosophy of language is in the center (understood as the value theory) and is defined, as a rule, by opposition internality, rooting in the Cartesian theory mental, and externalists presented in the 80th years. With Kripke, D. Kaplan, H. Patnem, etc., treatments of value. The latest analytical philosophy doesn't deny programs and the conceptual device of philosophy of language, cooperating with consciousness philosophy, action philosophy, logic philosophy, morals philosophy, and analytical metaphysics. The analysis of language is supplemented with the epistemic and other traditionally philosophical methods. The question of correlation of methods of the analysis of language with in tensional, transcendental and other methods of modern philosophy is raised. At the same time, since 80th years, are made attempts to deprive of it predominating situation. There were new directions of research - psychology philosophy (D. Dennet, D. Fodor, Ch. Chikhara), the theory of actions, a sociobiology, feminism (philosophy of social distinction) and the radical philosophy, investigating phenomenology of human perception and communication which suggest to find on a way of interdisciplinary research new prospects for the solution of philosophical problems.

Behind all this there are such authoritative names as I am Ya. Khintikka, D. Fyollesdal, G. Castaneda, J. Syorl, M. Foucault, G. Derrida, Zh. Delyoz, Zh. Lakan, P. de Mang. 
It is possible to claim that passes a stage of formation of new philosophy with various methods, discussing a problem of consciousness, knowledge and activity, a role the intentionality of concepts within the modern theory of language, the status of language community in knowledge, understanding of interrelation of scientific theories and cultural consciousness. The idea of the global phenomenological dialogue is its cornerstone, formulated in "philosophical anthropology" M. Bubera, "the dialogical project". From Frank and cult urological M. M. Bakhtin's concepts. In their works we see painful search of nonexistent concept of language which they designate the word "dialogue" and put the mass of efforts to describe the global process designated by this word (the mechanism, the natural phenomenon) corresponding to dialogue - an exchange of opinion between people, approximately as a multidimensional volume design - from one of the projections on the drawing.

The similar problem - research attempt only the global process partly learned by the person (the mechanism, the phenomenon), designated by the term "dialogue" - was solved in M. Heidegger's Dasein-analysis, M. Sheler's philosophical anthropology, "topmost psychology" L. S. Vygotsky, K. G. Jung's analytical psychology, philosophy of symbolical forms of E. Kassirer, P. A. Florenskogo and other philosophers of dialogue, for example, O. Rozenshtoka-Hyussi and E. Ebner, etc.

Logical dialogue - dialogue of minds; the phenomenological - dialogue of reasons. Phenomenological dialogue a direct exchange and the translation between personal integrity, the world's keeping the features; except them anything and anybody isn't present. The possibility of mutual understanding proved by semantic parallels, similar transcendental structures and similarity of the organizations of consciousness, doesn't guarantee adequacy of the translation. Completeness of understanding can be provided only with knowledge of language of "Another" in all its specifics. The analysis of evolution of the main strategy of the West European philosophy in the XX century brings us to thought that at the heart of philosophy of the XXI century use of the concept and mechanisms of phenomenological dialogue will lie.

For Cant reason is ability of formation of concepts, judgments, governed; reason is ability of formation of metaphysical ideas. Dialectics of reason and reason was developed by Gaggle: reason as more subzero capacity for abstractly-analytical dismemberment is the condition precedent of the higher, "reasonable", certainly-dialectical understanding. Reason quite often is understood, as ability to operate the prepared knowledge, reason - as work of new knowledge. Thus, dialogue in the modern understanding - foremost, phenomenological. In a logical dialogue connection comes true through speech (logos), and the guarantor of understanding is plenitude of reincarnation in a speech subject, that turns around a repression individual. A phenomenological dialogue is a direct exchange and translation between the personal unities, worlds saving the features; except talking nothing and nobody is present. Possibility of the mutual understanding, reasonable semantic parallels, similar transcendental structures and similarity of organizations of consciousness, does not avouch for adequacy of translation. Plenitude of understanding can be provided with only knowledge of language other in his entire specific.

The origin of philosophy is straight related to the logical dialogue that can be seen in influenced above sophistry conversation. In spite of permanent traction of philosophy to monism, a dialogue constantly showed up at creation of the philosophical systems (as, for example, dualism). The special attention to the range of problems of dialogue came to a head in humanity/pls under influence of literary criticism and hermeneutics. Modern humanitarian cognition lines up dialogic, for example, as a dialogue with tradition in a hermeneutics and history, coming true through an internal dialogue - thinking. Lately consideration of dialogic prospects is developed in ecology (dialogue with nature) and in culturelogical (dialogue of cultures, dialogue of civilizations). In our view, here concept a "dialogue" is traditionally used in his usual value (exchange by opinions) and not taken into account the fact of existence of the special natural phenomenon, phenomenon, cognition of basic conformities to law of display of that, in essence, begins only. In the end the XX century "philosophical" opening of natural science, conceptual transformations of his bases quite often take place as a result of the negative opening servings as a push to the revision of the folded looks and leaving point for passing to the opposite point of view. Proofs of impossibility, or not existences (be that in the theory of relativity, quantum mechanics or thermodynamics), showed that nature it is impossible to describe "from" outside, from positions of spectator. Description of nature is a living dialogue, communication, and she is inferior to limitations, testifying that we are the macroscopic creatures submerged in the real physical world.

Examining a phenomenological dialogue as combination of acts of generating and transformation of information is in the acts of cognition and management; it is possible to set next conformities to law. The change of variety of open system takes place on the synergetic laws of her co-operating with an environment and accompanied by the corresponding change of internal information of the system. 
Such change can be either a generation (at the height of variety) or dissipation (at reduction of variety). The generation of information takes place at mastering (self-knowledge) the system of the purchased variety, and this process consists of the mediated (through a variety) recognition and recoding of external information of environment in internal more valuable informative signs of efficiency, sense, knowledge (depending on the level of development attained by the system). Such recognition and recoding equivalently of generation of more valuable types of information and maybe only at presence of the program of development and in particular, program of generuting of information.

This program arises up in parallel with the height of variety of the system and kept in a system thesaurus. A thesaurus, as well as any memory, allows to keep and edit the programs placed in him along with data. Thus the variety of element composition of the system (data) grows due to materially-power metabolism under the management of the genetic program, and variety of connections (relations) between elements - due to informative metabolism under the management of the program of generuting of information functioning in accordance with general principle of programmatic management. Both programs are associate.

Thus, the achievement of effective management is possible during minimization and maximization of his energy. A search over of power optimum of management is brought to the extreme technical tasks of type by an "efficiency-complication-cost", where under efficiency, besides functional and other) technical - economical indexes, informing (entropy) of control system is understood also, under complication is a variety of managements, and under a cost is any resource pay after complication (power, economic, etc.).

Thus: - there is an optimal (maximal) relation efficiency/cost; -the insufficient variety of managements is harmful the same as and his superfluous surplus; - with the height of complication of the same type regulators their cost grows disproportionate quickly as compared to the height of management efficiency;

However "paying" for the programs is inevitable. Therefore the generalized informative principle of management, set forth V. B. Gukhmen, says of: a management is informative power optimally, if such variety of managements, at that a maximum of the management informing is potentially attainable on unit of resource costs, is chosen. Philosophical comprehension of conformities to law of phenomenological dialogue as processes of generuting and transformation of information and relations between her internal and external forms completed by rethinking of conformities to law of their interconversions.

For this purpose an elementary informative process is examined is one-sided connection: a source (internal information in form symbols) is $>$ " a coder (signs) ->" transmitter (signals) $->$ " environment (signals, hindrances) ->" a receiver (signs) is"'" a decoder (symbols) -"" consumer (internal information). This process is elementary, because plugged in all more difficult informative processes (bilateral, hierarchical, cellular, circular, ring to and other). If an informative process is accomplished in a materially-power form, then signs is sign interpretation of internal information of source, signals are materially-power carriers of codes. In without power informative processes of signs are symbols of the informative field, signals - without power carriers of these codes. Hindrances are revolting influences environments on white-fish.

Thus, dialogue as a process is establishment of understanding of source the consumer of information; connection as a result understands of source a consumer. From here - a problem of dialogue is hermeneutics problem. Understanding as an aim of dialogue implants adequacy of codes to the symbols, passed signals to the signs, accepted signals passed and, finally, reflections in a consumer to the represented source. Establishment of understanding implants reliability and rapid action of informative process.

For a dialogue as process transferrable information content is important, for connection as result her quality is important, i.e. value. The value of information is understood as a pragmatic relation between the system, her aim and information. The last possesses necessary for realization of aim properties and then more necessary properties, the more valuable information. From here a value of information is direct argument of her function of utility, qualificatory efficiency of the system. Exactly in this sense a value of information is a pragmatic relation.

Thus, conformities to law of processes of search and selection (choice) of necessary (valuable) information for the systems with a different aim, being the basis of mechanism of phenomenological dialogue, it is possible to take to the following: - the stage of arrangement of information (states of the system) is necessarily preceded an effective selection (to the search and selection); -a search and selection are taken to purposeful limitation of well-organized variety of the states of the system on a priori or adaptive criteria of value with the corresponding generation of selective information; - selective information at any eventual (effective) method of search and other equal terms is identical, a method determines only the expenses of time on a search; - selective information in number corresponds to "length" of the program of search, that depends on informing of the system and directly characterizes this informing. 
So, being base on results of researches of row of authors, generalized V. B. Guchman, we can define a phenomenological dialogue as a mechanism of unpower cooperations is in the difficult self-optimizing systems. Thus the dialogue of scientific method more determines direction of development of the conceptual systems, evolution of the modern scientific thinking.

An experiment comes forward not simply as a source of empiric facts or certificates, but also (that is especially important) as a carrier of specific communicative function in the system of developing scientific knowledge and cognition on the whole. Such dialogue communicative interpretation of experiment spills the new world on the integrative role of methods of scientific cognition as such.

From here is a personality aspect of dialogue. Today a dialogue is opened again as the special art of "inquiring" of nature; as an art that during human history (since time of invention of the written language) accepted very different forms. A dialogue way of thinking, certainly, is not the invention of science of our time. "Experiment and mathematical treatment. A question puts and gets an answer is already personality interpretation of process of natural-science knowledge and his subject (experimenter)", wrote M. M. Bakhtin.

\section{Conclusions}

A similar dialogue is an art, that cannot be it is entirely described by facilities of the formal logic how developed and perfect she was not. In this dialogue there are not the prepared answers for the asked questions, as be not final list of questions. Each of the parties engaged in such dialogue is not only asking or only answering. So that organization of similar dialogue with a necessity supposes unity of formal and informal methods of thinking, unity of logic and creative intuition.

During many centuries in philosophical knowledge used and interpreting a concept "dialogue-dispute": verbal or writing communication between two and more than people, containing an exchange ideas, persuasions, opinions. The aim of such dialogue was an attempt of one of parties to convince other of the rightness outspoken at the beginning of the idea. There is a row of philosophers in the first half of the XX century, investigating different questions in area of culture, art and anthropology, each in its own way, send to the conclusion about existence of some global phenomenon, for denotation of that a term was also used "dialogue".

\section{References}

Cole, M. (1999). Cultural-historical psychology: The science of the future. M.

Litvinenko, E. Y. (2000). Modern bilingualism as a dominant multicultural model of socialization: Dissertation of the doctor of sociological sciences (p. 250). Rostov-on-Don.

Olcott, M. B., \& Semenov, I. (2001, July). V. Malakhov Symbolic production of ethnicity and conflict in the book: Language and Ethnic Conflict (p. 132). Moscow Carnegie Center. M.: Gandalf.

Taylor, Ch. (1999). The Politics of Recogniton. In A. Gutmann (Ed.), Multicularalism and the Politics of Recognition. Princeton.

Thornberry P. International and Europe Standards on Minority Rights. (2004). In H. Miall (Ed.), Minority Rights in Europe: The Scope for a Transnational Regime (p. 24). London.

\section{Copyrights}

Copyright for this article is retained by the author(s), with first publication rights granted to the journal.

This is an open-access article distributed under the terms and conditions of the Creative Commons Attribution license (http://creativecommons.org/licenses/by/3.0/). 